\title{
Biological Activity of Bacillus thuringiensis (Berliner) Strains on Larvae and Adults of Ceratitis capitata (Wiedemann) (Diptera: Tephritidae)
}

\author{
Houda Aboussaid $^{1,2}$, Loubna El-Aouame ${ }^{1,2}$, Said El-Messoussi ${ }^{2}$, Khalid Oufdou ${ }^{1}$ \\ ${ }^{1}$ Laboratory of Biology and Biotechnology of Microorganisms, Cadi Ayyad University, Marrakech, Morocco; ${ }^{2}$ Laboratory of \\ Molecular Modeling and Ecophysiology, Faculty of Sciences-Semlalia, Cadi Ayyad University, Marrakech, Morocco. \\ Email: oufdou@ucam.ac.ma
}

Received August $9^{\text {th }}, 2010$; revised August $29^{\text {th }}, 2010$; accepted September $9^{\text {th }}, 2010$.

\begin{abstract}
The objective of this study was to evaluate the efficiency of Moroccan Bt strains against neonate larvae, third instar larvae and emerged adults of Ceratitis capitata. This Mediterranean fruit fly causes serious damages to Argan forest and other agricultural plants. There is no successful control program of this pest fly in the endemic Argan forest in Morocco. A single-dose test was performed on neonate larvae $(25 \mu \mathrm{L} / \mathrm{g})$ and adult $(333.33 \mu \mathrm{L} / \mathrm{g})$, when three doses of Bt toxins $(50 \mu \mathrm{L} / \mathrm{g}, 100 \mu \mathrm{L} / \mathrm{g}$ and $150 \mu \mathrm{L} / \mathrm{g})$ were tested against third instar of C. capitata. Among the twenty-six Bt strains examined, local Bt 13.4 and Bt A7 strains showed highest toxicity levels against larvae and adults, when compared to the reference strain, Bacillus thuringiensis subsp. israelensis HD567 "code 4Q1", and commercial product "Skeetal". One hundred percent mortality was observed against neonate larvae after 7 days of application by Bt 13.4 toxin. Third instar larvae were very susceptible to Bt A7 and Bt M-Ag 21.6 strains with $68 \%$ mortality (Lethal Concentration: $\left.L C_{50}=1.115\right)$ at a dose of $150 \mu \mathrm{L} / \mathrm{g}$. The Bt A7 strain was also highly toxic to adults with $81.66 \%$ of mortality after 7 days of application. This study demonstrated that some of our collection Bt strains can contribute to integrated C. capitata management system with strong biological control components.
\end{abstract}

Keywords: Argan Forest, Bacillus thuringiensis, Biological Control, Ceratitis capitata, Diptera

\section{Introduction}

Control of the Mediterranean fruit fly or medfly Ceratitis capitata (Wiedemann) (Diptera: Tephritidae); one of the world's most destructive insect, continues to rely on the use of broad-spectrum chemical insecticides in bait sprays [1]. While these chemical products are generally effective, they are controversial because of concerns for adverse effects on human health and non-target organisms, environmental pollution and development of insecticide resistance [2]. Therefore there is a need for alternative strategies such as bacterial entomopathogenic toxins: Bacillus thuringiensis.

Commercial preparations of $\mathrm{Bt}$ have been shown to be successful biological control products worldwide $[3,4]$. Bt insecticidal activity primarily lies in its parasporal crystals. They are predominantly composed of one or more types of proteins, known as $\delta$-endotoxins: the Cry proteins and the Cyt (cytolitic) proteins [5]. Nevertheless, other factors may contribute to Bt toxicity, such as the spore itself and extracellular soluble factors like $\beta$-exotoxins, VIP (vegetative insecticidal proteins) toxins, phospholipases, proteases and chitinases [6].

Cry toxins are highly specific to their target insects, are harmless to humans, vertebrates and plants, and are easily biodegradable [7]. To date, several invertebrates have been described to be susceptible to Bt strains, mostly insects from Lepidoptera, Diptera and Coleoptera, but also from other orders (Hymenoptera, Homoptera, Orthoptera and Mallophaga) and also species from nematodes, mites and protozoa. However, for many crystal-bearing Bt strains, no toxic activity has been detected yet [8]. Thus, in recent decades, there has been a great interest in the screening of Bt collections to find isolates useful for pest control [9-12]. Many dipteran species have been found to be susceptible to $\mathrm{Bt}$; these 
include mosquitoes, blackflies, chironomids, tipulids, muscids, sciarids, drosophilids [13] and tephritidis; such as the olive fly Bactrocera oleae $[14,15]$, the Mexican fruit fly Anastrepha ludens [16,17] and the Mediterranean fruit fly C. capitata [18-20].

According to our knowledge, there is no available data on the effect of Moroccan Bt strains isolated especially from the endemic Argan forest which is strongly infested by $C$. capitata.

In the present study, we evaluate the biological entomopathogenic activity of Bt strains isolated from Marrakech region and Argan region in Morocco. We test the insecticidal effects of $\mathrm{Bt}$ strains against neonate larvae, third instar larvae and emerged adults of $C$. capitata.

\section{Materials and Methods}

\subsection{Insect Rearing}

The insects used in the bioassays came from the laboratory colony of $C$. capitata, maintained at the Faculty of Sciences Semlalia, Cadi Ayyad University, Marrakech (Morocco).

The laboratory conditions used for rearing and bioassays were $25 \pm 1{ }^{\circ} \mathrm{C}, 60 \pm 10 \%$ relative humidity (RH) and $12 \mathrm{~h}$ of light and $12 \mathrm{~h}$ of darkness. Eggs laid through a net placed on one side of an insect-rearing cage were collected in a plastic container that was filled with distilled water. Larvae from $0.5 \mathrm{ml}$ of eggs were raised on an artificial diet containing $250 \mathrm{~g}$ wheat bran, $70 \mathrm{~g}$ sucrose, $36.3 \mathrm{~g}$ brewer's yeast, $2.8 \mathrm{~g}$ (methyl 4-hydroxybenzoate; Sigma), 2.8 g Nipasol (propyl 4-hydroxybenzoate; Sigma) nipagin, $2.5 \mathrm{~g}$ Benzoic acid and $600 \mathrm{~mL}$ distilled water.

Third-instar larvae were transferred into a pupation chamber with sand and were maintained there for at least 1 week before they were collected using a sieve. Adult flies were fed an artificial diet comprised of $20 \%(\mathrm{wt} / \mathrm{wt})$ yeast autolysate and $80 \%(\mathrm{wt} / \mathrm{wt})$ sucrose. Water was provided to the flies via a damp yellow sponge.

\subsection{B. thuringiensis Strains}

Samples were collected from different areas of Marrakesh region and endemic argan forests (southwest of Morocco) (Table 1). Sampling was performed from heterogeneous sources: soils underground surface (to avoid spore inactivation caused by UV radiation), Citrus Phyllplane, Farm animal excrement, wastewater and sludge of wastewater treatment system.

$\mathrm{Bt}$ isolation was carried out as described previously by Bel et al. [21]. Colonies with characteristic Bt morphology and presence of parasporal inclusions in the sporangium were selected and plated again for single colony isolation. After a second microscopic observation to ver-
Table 1. Local Bt strains isolated from different habitats in Morocco.

\begin{tabular}{cccc}
\hline Localisation & Habitat & $\begin{array}{c}\text { No. of } \\
\text { samples }\end{array}$ & $\begin{array}{c}\text { No. of Bt } \\
\text { isolates }\end{array}$ \\
\hline Agadir & Argan soils & 8 & 13 \\
Essaouira & Argan soils & 2 & 4 \\
& Olive-cultivated soil & 1 & 3 \\
& $\begin{array}{c}\text { Bean-cultivated soil } \\
\text { Farm animal }\end{array}$ & 1 & 1 \\
Marrakech & $\begin{array}{c}\text { excrement } \\
\text { Citrus phylloplane }\end{array}$ & 1 & 1 \\
& $\quad$ Wastewater & 1 & 1 \\
& $\begin{array}{c}\text { Sludge of wastewater } \\
\text { treatment system }\end{array}$ & 2 & 2 \\
& Total & 17 & 26 \\
\hline
\end{tabular}

ify presence of protein inclusions, strains were cultured in CCY (Casein Casein Yeast) liquid medium [22], for 2 days until sporulation. Vegetative cells were eliminated by heating the sample at $70^{\circ} \mathrm{C}$ for $20 \mathrm{~min}$. Aliquots were taken and stored in $25 \%$ glycerol at $-20^{\circ} \mathrm{C}$.

The standard strains, other than those isolated in this study were Bacillus thuringiensis subsp. israelensis HD 567 (code 4Q1, Bacillus Genetic Stock Center, B.G.S.C., Ohio State University, Columbus, OH, U.S.A.) and Skeetal, a commercial product based on B. thuringiensis subsp. israelensis (Valent Biosciences Corporation, Libertyville, U.S.A.).

\subsection{Culture Conditions and Production of Spore - Crystal Biomass}

A loopful of cells from a single colony of each strain grown in CCY agar medium were inoculated in $4.5 \mathrm{ml}$ of liquid CCY medium (pre-culture) and grown for $48 \mathrm{~h}$ at $28^{\circ} \mathrm{C}$ and agitated at $200 \mathrm{rpm}$. An aliquot was taken to verify spore and crystal formation (over $90 \%$ sporulation is optimum), and the pre-culture was incubated for 20 $\min$ at $70^{\circ} \mathrm{C}$ to eliminate vegetative cells (synchronization).

The main culture $(40 \mathrm{ml})$ was inoculated with $1 / 1,000$ volumes of synchronized pre-culture and grown as mentioned above. Optimal crystal formation was checked by phase-contrast microscopy (DM2500, Leica Microsystems, Germany). The total number of cells in a culture was determined by plating 10-fold serial dilutions on CCY plates. Then the whole culture was centrifuged at $9,000 \times \mathrm{g}$ for $10 \mathrm{~min}$.

The pellet was washed once with ice-cold $1 \mathrm{~mol} / \mathrm{l}$ $\mathrm{NaCl}, 10 \mathrm{mmol} / \mathrm{l}$ EDTA solutions. Finally, the pellet was suspended in $1 \mathrm{ml}$ of $10 \mathrm{mmol} / 1 \mathrm{KCl}$. Optical Density 
(OD) was measured at $600 \mathrm{~nm}$ and the suspensions were stored at $-20^{\circ} \mathrm{C}$ until bioassay. All steps after centrifugation were done on ice to limit proteolysis.

\subsection{Bioassays}

In order to determine and optimize the toxicity of $26 \mathrm{Bt}$ strains, three kinds of bioassays were carried out:

\subsubsection{Activity against First Instar Larvae}

A single-dose test was performed; about $50 \mu \mathrm{L}$ of the culture of each strain corresponding to $1.9 \cdot 10^{8} \mathrm{UFC} / \mathrm{mL}$ added onto $2 \mathrm{~g}$ of the artificial diet surface contained in 24-well polystyrene plates. One-first instar larvae of $C$. capitata was added per well, and the mortality was recorded after 7 days of incubation at $25^{\circ} \mathrm{C}$ in dark conditions. Two replicates of 24 larvae were conducted for each Bt strain.

B. thuringiensis subsp. israelensis HD567 strain (Bti) (B.G.S.C. code 4Q1) and Skeetal, a commercial product based on Bti and reported to be active against dipterans, were used as standard controls. Sterile distilled water was used as a negative control.

\subsubsection{Activity against Third Instar Larvae}

Five third instar larvae were transferred to plastic recipients $(30 \mathrm{~mm}$ diam $\times 70 \mathrm{~mm}$ depth) containing $10 \mathrm{~g}$ of diet (see insect rearing) mixed with the toxin, except for the control group, which had just received water with the diet. Three doses of Bt spore-crystals $(50 \mu \mathrm{L} / \mathrm{g}, 100 \mu \mathrm{L} / \mathrm{g}$ and $150 \mu \mathrm{L} / \mathrm{g}$ ) were used in five repetitions for each strain to confirm the results. The recipients were covered with nylon mesh, and fixed around the edges with a rubberband.

After $48 \mathrm{~h}$ of exposure, the number of dead larvae was counted and the pupae were separated from diet and then transferred to Petri dish $(9 \mathrm{~cm})$, until adult emergence. Bioassay tests were carried out to determine $\mathrm{LC}_{50}$ values of the Bt strains against $C$. capitata larvae.

\subsubsection{Activity against $C$. capitata Adults}

20 adults newly emerged (1-2 days old) were kept in the cage $(25 \mathrm{~cm}$ by $25 \mathrm{~cm})$ containing artificial diet (see insect rearing) mixed with $333.33 \mu \mathrm{L} / \mathrm{g}$ of spores and crystals mixture. The sweet substances (hydrolyzed protein and sugar) was used in the bioassay to attract the adults recently emerged to feed Bt spore-crystal. Water was provided to the flies via a damp yellow sponge. For each toxin, a negative control was prepared with distilled water and fly feeding. Three replicates per assay were carried out. Fly mortality was recorded daily for 7 days.

\subsection{Statistical Analysis}

The mortality assay was calculated according to the Ab- bot's formula:

Mortality corrected $\%=(1-\mathrm{n}$ in T after treatment $/ \mathrm{n}$ in Co after treatment $) * 100$

Where: $\mathrm{n}=$ Insect population, $\mathrm{T}=$ treated, $\mathrm{Co}=\mathrm{con}-$ trol.

The $\mathrm{LC}_{50}$ regression equation and the $95 \%$ confidence limit were calculated by using Probit analysis. Percentages of mortality obtained from bioassay tests were analyzed using one-way analysis of variance (ANOVA, $p<$ $0.05)$. Tukey's test $(p<0.05)$ was used to analyze f significant differences among the Bt strains tested against $C$. capitata.

\section{Results}

\subsection{Activity against First Instar Larvae}

Results of the larvicidal effectiveness of $26 \mathrm{Bt}$ strains are shown in Table 2.

The spore-crystal mixture of selected strains showed significantly larvicidal activity (df: 27, F: 10.42, $p<$ 0.005 at $95 \%$ ). The mortality rate was ranging from 8.33 to $100 \%$, obtained after 7 days of treatment with single dose $25 \mu \mathrm{L} / \mathrm{g}$. The toxin produced by Bt 13.4 strain showed the highest effect, with $100 \%$ of corrected mortality. The effect of Bt 2.1 strain was the lowest, with $8.33 \%$ as percentage of larval mortality. The reference strain 4Q1 (45.83\%) and Skeetal (60.83\%) caused mortality to the same degree with some of our strains or low like Bt M-Ag 2.7 (47.92\%).

\subsection{Activity against Third Instar Larvae}

Screening for toxicity against $C$. capitata adults was performed using spore-crystal mixture. In Table 3, the results of bioassays on the biological activity of $\mathrm{Bt}$ strains tested against $C$. capitata third instar larvae are presented.

The susceptibility of third instar of $C$. capitata, evaluated as percentage of larvae that did not survive to adulthood, varied significantly between $0-8 \%, 8-48 \%$ $20-68 \%$ at dosages of $50 \mu \mathrm{L} / \mathrm{g}, 100 \mu \mathrm{L} / \mathrm{g}$ and $150 \mu \mathrm{L} / \mathrm{g}$ respectively (Table 3). At $150 \mu \mathrm{L} / \mathrm{g}$, Bt A7 and Bt M-Ag 21.6 strains proved most effective activity $(68 \%)$ whereas Bt A10 strain showed the lowest corrected mortality $(20 \%)$.

The $\mathrm{LC}_{50 \mathrm{~s}}$ determined after $48 \mathrm{~h}$ of application were ranging between $1.115 \mu \mathrm{L} / \mathrm{g}$ for Bt A7 and $3.199 \mu \mathrm{L} / \mathrm{g}$ for Bt A14. Significant differences were noted with tested doses (df: 2, F: 49.97, $p<0.005$ at 95\%).

\subsection{Activity against $C$. capitata Adults}

Table 4 shows biological activity of the spore-crystal mixture of Bt strains in newly emerged adults of $C$. 
Table 2. Entomopathogenic activity of the spore-crystal mixture of Bt strains against newly emerged larvae of $C$. capitata.

\begin{tabular}{|c|c|c|c|}
\hline \multirow{2}{*}{ Bt strains } & \multirow{2}{*}{ Mortality $^{\mathrm{a}}(\%) \pm \mathrm{SE}$} & \multicolumn{2}{|c|}{ 95\% Confidence Limits } \\
\hline & & Lower & Upper \\
\hline Skeetal & $60.83 \pm 0.04824^{\mathrm{bcd}}$ & 0.778 & 0.6725 \\
\hline $4 Q 1$ & $45.83 \pm 0.05924^{\mathrm{abd}}$ & 0.3316 & 0.6228 \\
\hline Bt A7 & $95.83 \pm 0.02915^{\mathrm{a}}$ & 0.8997 & 0.8997 \\
\hline Bt M-Ag 4.1 & $85.42 \pm 0.05148^{\mathrm{abc}}$ & 0.7506 & 0.9577 \\
\hline Bt 32.3 & $87.50 \pm 0.04824^{\mathrm{abc}}$ & 0.778 & 0.972 \\
\hline Bt A14 & $66.67 \pm 0.06876^{\mathrm{hi}}$ & 0.528 & 0.805 \\
\hline Bt A10 & $77.08 \pm 0.0613^{1 \mathrm{i}}$ & 0.6475 & 0.8942 \\
\hline Bt M-Ag 2.2 & $85.42 \pm 0.03531^{\mathrm{abc}}$ & 0.8665 & 1.0085 \\
\hline Bt M-Ag 26.4 & $77.08 \pm 0.06131^{\mathrm{bcd}}$ & 0.6475 & 0.8942 \\
\hline Bt M-Ag 21.6 & $77.08 \pm 0.06131^{\mathrm{bc}}$ & 0.6475 & 0.8942 \\
\hline Bt M-Ag 2.4 & $87.50 \pm 0.04824^{\mathrm{abc}}$ & 0.778 & 0.972 \\
\hline Bt A9 & $75.00 \pm 0.06316^{\mathrm{cde}}$ & 0.6229 & 0.8771 \\
\hline Bt A11 & $66.67 \pm 0.06876^{\mathrm{efg}}$ & 0.5283 & 0.805 \\
\hline Bt M-Ag 2.1 & $8.33 \pm 0.04031^{\mathrm{fgh}}$ & 0.0022 & 0.1644 \\
\hline Bt M-Ag 2.7 & $47.92 \pm 0.07287^{\text {ghi }}$ & 0.3326 & 0.6258 \\
\hline Bt 7.16 & $62.50 \pm 0.07062^{\mathrm{efg}}$ & 0.4829 & 0.7671 \\
\hline Bt 11.3 & $66.67 \pm 0.0719^{\mathrm{cde}}$ & 0.4387 & 0.728 \\
\hline Bt 32.7 & $75.00 \pm 0.06316^{\mathrm{cde}}$ & 0.6229 & 0.8771 \\
\hline Bt 10.3 & $95.83 \pm 0.02915^{\mathrm{abc}}$ & 0.8997 & 1.017 \\
\hline Bt 13.4 & $100.00 \pm 0.0000^{\mathrm{abc}}$ & 1.000 & 1.000 \\
\hline Bt 16.1 & $79.17 \pm 0.05924^{\mathrm{bcd}}$ & 0.6725 & 0.9108 \\
\hline Bt B1 & $81.25 \pm 0.05693^{\mathrm{bcd}}$ & 0.698 & 0.927 \\
\hline Bt B6 & $83.33 \pm 0.04824^{\mathrm{fgh}}$ & 0.778 & 0.972 \\
\hline Bt B9 & $83.33 \pm 0.05436^{\mathrm{fgh}}$ & 0.724 & 0.9427 \\
\hline Bt M-Ag 1.7 & $66.67 \pm 0.06876^{\mathrm{abc}}$ & 0.5283 & 0.805 \\
\hline Bt M1 & $79.17 \pm 0.04824^{\mathrm{abc}}$ & 0.778 & 0.972 \\
\hline Bt M5 & $68.57 \pm 0.06761^{\mathrm{hi}}$ & 0.5515 & 0.8235 \\
\hline Bt M12 & $87.50 \pm 0.04824^{\mathrm{cdi}}$ & 0.778 & 0.972 \\
\hline
\end{tabular}

a: ${ }^{\text {a,b }}$ Mean values from the same row with different letters in superscript are significantly different according to Tukey test $(p<0.05)$. Means followed by the same letter in columns are not different from each other by the Tukey's test at $5 \%$ significance. 
Biological activity of Bacillus thuringiensis (Berliner) strains on larvae and adults of Ceratitis capitata (Wiedemann)

(Diptera: Tephritidae)

Table 3. Entomopathogenic activity of the spore-crystal mixture of Bt strains against last instar larvae of $C$. capitata.

\begin{tabular}{|c|c|c|c|c|c|}
\hline \multirow{2}{*}{ Strains } & \multicolumn{3}{|c|}{ Mortality $(\%) \pm \mathrm{SE}$} & \multirow{2}{*}{$\mathbf{L C}_{50}$} & \multirow{2}{*}{ 95\% Confidence Limits } \\
\hline & $50 \mu \mathrm{L} / \mathrm{g}$ & $100 \mu \mathrm{L} / \mathrm{g}$ & $150 \mu \mathrm{L} / \mathrm{g}$ & & \\
\hline Skeetal & $0 \pm 0.0000$ & $36 \pm 1.30384$ & $52 \pm 1.14018$ & 1.328 & $1.143 \pm 1.650$ \\
\hline $4 Q 1$ & $0 \pm 0.0000$ & $28 \pm 0.89443$ & $40 \pm 0.0000$ & 1.351 & $1.144 \pm 1.833$ \\
\hline Bt A7 & $8 \pm 54772$ & $48 \pm 54772$ & $68 \pm 54772$ & 1.115 & $0.938 \pm 1.370$ \\
\hline Bt M-Ag 4.1 & $1 \pm 0.0000$ & $40 \pm \quad 0.0000$ & $60 \pm 0.0000$ & 1.250 & $1.067 \pm 1.554$ \\
\hline Bt 32.3 & $4 \pm 0.44721$ & $36 \pm 0.44721$ & $60 \pm 0.0000$ & 1.268 & $1.028 \pm 1.833$ \\
\hline Bt A14 & $4 \pm 0.44721$ & $12 \pm 0.54772$ & $24 \pm 0.83666$ & 3.199 & $1.738 \pm \% 100000002.000 \mathrm{E}+12 *$ \\
\hline Bt A10 & $0 \pm 0.0000$ & $8 \pm 0.54772$ & $20 \pm 0.70711$ & 2.394 & $1.656 \pm 4815083.000$ \\
\hline Bt M-Ag 2.2 & $4 \pm 0.44721$ & $44 \pm 0.44721$ & $60 \pm 0.0000$ & 1.212 & $1.007 \pm 1.592$ \\
\hline Bt M-Ag 26.4 & $8 \pm 0.54772$ & $28 \pm 0.54772$ & $40 \pm 0.0000$ & 1.852 & $1.298 \pm 11.893$ \\
\hline Bt M-Ag 21.6 & $0 \pm 0.0000$ & $44 \pm 0.44721$ & $68 \pm 0.54772$ & 1.164 & $1.001 \pm 1.381$ \\
\hline Bt M-Ag 2.4 & $8 \pm 0.54772$ & $36 \pm 0.44721$ & $60 \pm 0.70711$ & 1.268 & $1.028 \pm 1.833$ \\
\hline Bt A9 & $0 \pm 0.0000$ & $28 \pm 0.54772$ & $40 \pm 0.70711$ & 1.604 & $1.297 \pm 2.886$ \\
\hline Bt A11 & $0 \pm 0.0000$ & $24 \pm 0.44721$ & $32 \pm 0.54772$ & 1.847 & $1.413 \pm 5.420$ \\
\hline Bt M-Ag 2.1 & $0 \pm 0.0000$ & $28 \pm 0.54772$ & $32 \pm 0.54772$ & 1.164 & $1.001 \pm 1.381$ \\
\hline Bt M-Ag 2.7 & $0 \pm 0.0000$ & $16 \pm 0.44721$ & $32 \pm 0.54772$ & 1.872 & $1.458 \pm 6.085$ \\
\hline Bt 7.16 & $0 \pm 0.0000$ & $20 \pm 0.70711$ & $36 \pm 0.44721$ & 1.743 & $1.390 \pm 3.959$ \\
\hline Bt 11.3 & $0 \pm 0.0000$ & $16 \pm 0.44721$ & $52 \pm 0.54772$ & 1.464 & $1.273 \pm 2.005$ \\
\hline Bt 32.7 & $0 \pm 0.0000$ & $16 \pm 0.44721$ & $53 \pm 0.54772$ & 1.464 & $1.273 \pm 2.005$ \\
\hline Bt 10.3 & $4 \pm 0.44721$ & $24 \pm 0.83666$ & $60 \pm 0.70711$ & 1.360 & $1.137 \pm 1.877$ \\
\hline Bt 13.4 & $0 \pm 0.0000$ & $32 \pm 0.54772$ & $64 \pm 0.44721$ & 1.264 & $1.094 \pm 1.532$ \\
\hline Bt 16.1 & $4 \pm 0.44721$ & $16 \pm 0.44721$ & $52 \pm 0.54772$ & 1.548 & $1.260 \pm 2.603$ \\
\hline Bt B1 & $4 \pm 0.44721$ & $20 \pm 0.70711$ & $52 \pm 0.54772$ & 1.515 & $1.231 \pm 2.490$ \\
\hline Bt B6 & $0 \pm 0.0000$ & $8 \pm 0.54772$ & $44 \pm 0.44721$ & 1.574 & $1.376 \pm 2.400$ \\
\hline Bt B9 & $0 \pm 0.0000$ & $12 \pm 0.54772$ & $40 \pm 0.70711$ & 1.654 & $1.391 \pm 3.203$ \\
\hline Bt M-Ag 1.7 & $0 \pm 0.0000$ & $36 \pm 0.83666$ & $56 \pm 0.44721$ & 1.313 & $1.117 \pm 1.695$ \\
\hline Bt M1 & $0 \pm 0.0000$ & $28 \pm 0.54772$ & $56 \pm 0.44721$ & 1.362 & $1.169 \pm 1.768$ \\
\hline Bt M5 & $0 \pm 0.0000$ & $8 \pm 0.54772$ & $28 \pm 0.54772$ & 1.947 & $1.529 \pm 18.077$ \\
\hline Bt M12 & $4 \pm 0.44721$ & $12 \pm 0.54772$ & $52 \pm 0.54772$ & 1.580 & $1.288 \pm 2.723$ \\
\hline
\end{tabular}

a: ${ }^{\text {a,b }}$ Mean values from the same row with different letters in superscript are significantly different according to Tukey test $(p<0.05)$. Means followed by the same letter in columns are not different from each other by the Tukey's test at 5\% significance. *: Upper limits greater than or equal to $1 . E 20$ are really infinite 
Table 4. Entomopathogenic activity of the spore-crystal mixture of Bt strains against emerged adults of $C$. capitata.

\begin{tabular}{|c|c|c|c|}
\hline \multirow{2}{*}{ Strains } & \multirow{2}{*}{ Mortality (\%) $\pm \mathrm{SE}$} & \multicolumn{2}{|c|}{ 95\% Confidence Limits } \\
\hline & & Lower & Upper \\
\hline Skeetal & $48.33 \pm 0.2801^{\mathrm{bc}}$ & 0.7967 & 1.9652 \\
\hline $4 Q 1$ & $33.33 \pm 0.25332^{\mathrm{bc}}$ & 0.424 & 1.4808 \\
\hline Bt A7 & $81.66 \pm 0.52834^{\mathrm{a}}$ & 1.4217 & 3.6259 \\
\hline Bt M-Ag 4.1 & $80 \pm 0.43799^{\mathrm{a}}$ & 1.2292 & 3.0565 \\
\hline Bt 32.3 & $70 \pm 0.371^{\mathrm{c}}$ & 1.3213 & 2.8691 \\
\hline Bt A14 & $68 \pm 0.55838^{c}$ & 1.2162 & 3.5457 \\
\hline Bt A10 & $60 \pm 0.347 \mathrm{ca}$ & 1.1333 & 2.581 \\
\hline Bt M-Ag 2.2 & $80 \pm 0.53282^{\mathrm{a}}$ & 1.3647 & 3.5876 \\
\hline Bt M-Ag 26.4 & $70 \pm 0.4555^{\mathrm{c}}$ & 1.4784 & 3.3787 \\
\hline Bt M-Ag 21.6 & $80 \pm 0.4555^{\mathrm{a}}$ & 1.4784 & 3.3787 \\
\hline Bt M-Ag 2.4 & $80 \pm 0.59074^{\mathrm{a}}$ & 0.9106 & 3.3751 \\
\hline Bt A9 & $60 \pm 0.4555^{\text {ca }}$ & 1.4784 & 3.3787 \\
\hline Bt A11 & $56.66 \pm 0.347^{\mathrm{d}}$ & 1.1333 & 2.581 \\
\hline Bt M-Ag 2.1 & $68.66 \pm 0.32819^{\mathrm{ca}}$ & 1.1249 & 2.4941 \\
\hline Bt M-Ag 2.7 & $78.66 \pm 0.371^{\mathrm{a}}$ & 1.3213 & 2.8691 \\
\hline Bt 7.16 & $75 \pm 0.56625^{\mathrm{a}}$ & 1.1522 & 3.5145 \\
\hline Bt 11.3 & $70 \pm 0.45848^{\mathrm{c}}$ & 1.3293 & 3.2421 \\
\hline Bt 32.7 & $75 \pm 0.59074^{\mathrm{a}}$ & 0.9106 & 3.3751 \\
\hline Bt 10.3 & $81.66 \pm 0.30971^{\mathrm{a}}$ & 1.6397 & 2.9318 \\
\hline Bt 13.4 & $80 \pm 0.53282^{\mathrm{a}}$ & 1.3647 & 3.5876 \\
\hline Bt 16.1 & $80 \pm 0.4555^{\mathrm{a}}$ & 1.4784 & 3.3787 \\
\hline Bt B1 & $80 \pm 0.4555^{\mathrm{a}}$ & 1.4784 & 3.3787 \\
\hline Bt B6 & $75 \pm 0.40908^{a}$ & 1.4324 & 3.139 \\
\hline Bt B9 & $80 \pm 0.26342^{\mathrm{a}}$ & 1.8791 & 2.978 \\
\hline Bt M-Ag 1.7 & $81.66 \pm 0.4555^{\mathrm{a}}$ & 1.4784 & 3.3787 \\
\hline Bt M1 & $81.66 \pm 0.53282^{\mathrm{a}}$ & 1.3647 & 3.5876 \\
\hline Bt M5 & $60 \pm 0.347^{\mathrm{ca}}$ & 1.1333 & 2.581 \\
\hline Bt M12 & $80 \pm 0.33503^{\mathrm{a}}$ & 1.7297 & 3.1274 \\
\hline
\end{tabular}

$\mathrm{a}:{ }^{\mathrm{a}, \mathrm{b}}$ Mean values from the same row with different letters in superscript are significantly different according to Tukey test $(p<0.05)$. Means followed by the same letter in columns are not different from each other by the Tukey's test at 5\% significance. 
capitata.

The difference of fly's mortality was significantly higher between those exposed to the spore-crystal mixtures and the ones exposed to the water control.

The majority of Bt strains killed more than $50 \%$ of $C$. capitata adults. The mortality values varied significantly between strains. They produced significant mortalities from 56.66 to $81.66 \%$ (df: 27, F: $0.68, p<0.005$ at $95 \%$ ); when using both spore-crystal suspensions of Bt toxin after 7 days exposure time. The more toxic Bt strains caused adult mortality starting from the $2^{\text {nd }}$ day or the $3^{\text {rd }}$ day of ingestion.

The commercial product based on Bti (Skeetal) and the reference Bti strain (code 4Q1) were also tested against $C$. capitata adults. They were in general less efficient, showing corrected mortality about $48.33 \%$ and $33.33 \%$ respectively (Table 4 ).

\section{Discussion}

During sporulation, the Gram-positive bacterium, Bt forms crystalline protein inclusions, which possess insecticidal activity. These parasporal inclusions differentiate this species from other related species such as Bacillus cereus and Bacillus mycoides [23]. The crystals are generally smaller than the spores and can represent $\pm 30 \%$ of the dry weight of the cell [24].

A total of $26 \mathrm{Bt}$ strains were tested on both larvae and adults; and it was found that $100 \%$ of strains were toxic against adults of $C$. capitata, $92 \%$ on neonate larvae on adults, and $60 \%$ on third instar larvae. Neonate larvae and adults were more susceptible than third instar larvae of C. capitata; in fact, several strains produced high mortality only after 3 days of exposure. The toxicity of spore-crystal mixtures against third larvae was seldom high but some strains yielded $68 \%$ mortality after 48 hours of application at the doses used in these experiments.

The biological activity of Bt strains has been studied by many authors, who determined the insecticide potential of obtained toxins using both spore and crystal. Our results are similar to that reported by Gingrich [18]. This author have tested 94 strains of Bt and found that 15 of them killed at least $80 \%$ of $C$. capitata adults that fed pellets for 9 days.

Hassani and Gaouar Benyelles [19] have tested the effect of the preparation of Bti on wild third instar larvae and adults of $C$. capitata isolated from Citrus fruit orchards in Algeria, and observed toxicity in high doses $(100 \mathrm{mg} / \mathrm{g})$ with a reduction in average emergence $(84.62 \%)$, concluding that the stage $\mathrm{L}_{3}$ and adults of the pest are very susceptible at this dose of Bti product.
Molina et al. [25] have tested sporulated cultures of 115 bacterial strains of Bacillus pumilus $\left(4.65 \times 10^{8}\right.$ to $1.45 \times 10^{7} \mathrm{CFU} / \mathrm{mL}$ ) against adults and neonate larvae of C. capitata. None of these strains were caused significant mortality of $C$. capitata adults compared with the negative controls. The mortality rates with the 115 bacterial strains at the end of the experiment ranged from $0 \%$ to $40 \%$, while the average mortality rates with the negative controls ranged from $5 \%$ to $30 \%$. Similar results were obtained in bioassays with larvae, the maximal corrected mortality rates with the 115 bacterial isolates ranged from $0 \%$ to $36 \%$, while the average mortality rates with the negative controls ranged from $1 \%$ to $12 \%$ after 15 days, at the end of the experiment. After this toxicity screening, they obtained a novel Bacillus pumilus strain, which is highly toxic to $C$. capitata larvae. The mortality rate for $C$. capitata larvae ranged from 68 to $94 \%$ depending on the conditions under which the culture was kept before the bioassay.

Karamanlidou et al. [14] and Yamvrias and Anagnou [26] have reported a mortality $>80 \%$ when they used various $\mathrm{Bt}$ strains against old larvae of the dipteran olive fruit fly, B. oleae (Gmelin). Robacker et al. [16] evaluated the action of $55 \mathrm{Bt}$ strains on larvae of Mexican fruit fly, Anastrepha ludens (Loew). Only 7 strains were found toxic on adults; the centrifuge pellets or precipitates of Bt strains have killed $>50 \%$ of larvae. The mortality rates varied between 4 to $62 \%$ after application of the pellets of these strains against adult flies. Only 5 of them killed $65-80 \%$ of adults in 10 days compared with $2.7 \%$ mortality in controls. The other killed $40 \%$ of adults in the same experiment.

Alberola et al. [15] studied the Bt activity against second instar of $B$. oleae larvae and new emerged adults. These authors have reported that both spore-crystal mixtures $(10 \% \mathrm{~mL})$ caused $70 \%$ mortality for larvae in 72 hours and $80 \%$ of mortality for adult flies in 6 to 10 days of application.

The obtained results during our study showed that some Bt strains were most toxic against adults than on larvae and vice versa. For example, the insecticidal activity of Bt M-Ag 2.1 against larvae of C. capitata is 8.33, whereas the activity of this strain towards $C$. capitata adults is 68.66 (Tables 2 and 4). The genes which coding for insecticidal activity against the two stages of the medfly, could be different $[15,16]$. Alberola et al. [15] have also reported that there are some different chemical conditions in the gut of the two stages of the insect that can control the activation or activity of the protoxin.

On the other hand, some Bt strains expressed high activities against the both stages of $C$. capitata such as Bt 
A7, Bt 13.4, Bt M-Ag 4.1, Bt M-Ag 2.2, Bt M-Ag 21.6 (Tables 2 and 4 ).

\section{Conclusions}

Sustainable agriculture will rely increasingly to biological control of pests such as $C$. capitata that is considered as a quarantine pest over the world and particularly in the Argan area. No control program has been undertaken until now against $C$. capitata in the Argan forest. The use of biopesticides is environmentally friendly and reduces the contact of human to chemical pesticides. The present study provides evidence for the insecticidal activity of Moroccan Bt strains against $C$. capitata. Some Bt strains showed a great activity against neonate larvae, third instar larvae and especially towards adults of $C$. capitata. A number of our collection Bt strains showed high insecticidal activity against $C$. capitata in comparison to that noted for the Bti HD567 strain and the commercial product Skeetal previously used in the control of harmful fruit flies. Some of our Bt strains can be used in the biological control system to fight against $C$. capitata and may contribute to reduce the use of chemical insecticides harmful to the consumers and the environment.

\section{REFERENCES}

[1] J. P. Ros, E. Wong, J. Olivero and E. Castillo, "Mejora de los Mosqueros, Atrayentes y Sistemas de Retención Contra la Mosca Mediterránea de la Fruta Ceratitis capitata Wied. Como Hacer de la Técnica del Trampeo Masivo una Buena Herramienta Para Controlar esta Plaga," Boletín Sanidad Vegetal Plagas, Vol. 28, No. 4, 2002, pp. 591-597.

[2] C. Magaña, P. Hernández-Crespo, A. Brun-Barale, F. Couso-Ferrer, J. M. Bride, P. Castañera, R. Feyereisen and F. Ortego, "Mechanisms of Resistance to Malathion in the Medfly Ceratitis capitata," Insect Biochemisry and Molecular Biology, Vol. 38, No. 8, 2008, pp. 756-762.

[3] V. Sanchis, and D. Bourguet, "Bacillus thuringiensis: Applications in Agriculture and Insect Resistance Management," Agronomy for Sustainable Development, Vol. 28, No. 1, 2008, pp. 11-20.

[4] K. van Frankenhuyzen, "Insecticidal Activity of Bacillus thuringiensis Crystal Proteins," Journal of Invertebrate Pathology, Vol. 101, No. 1, 2009, pp. 1-16.

[5] N. Crickmore, D. R. Zeigler, J. Feitelson and E. Schnepf, "Revision of the Nomenclature for the Bacillus thuringiensis Pesticidal Crystal Proteins," Microbiology and Molecular Biology Reviews, Vol. 62, No. 3, 1998, pp. 807-813.

[6] M. Porcar and V. M. Juárez-Pérez, "PCR-Based Identification of Bacillus thuringiensis Pesticidal Crystal Genes," FEMS Microbiology Reviews, Vol. 26, No. 5, 2003, pp. 419-432.
[7] IPSC-WHO, “Bacillus thuringiensis. Environmental Health Criteria of the International Program on Chemical Safety," IPCS WHO International Program on Chemical Safety, No. 217. 1999.

[8] E. Schnepf, N. Crickmore, J. Van Rie and D. Lereclus, "Bacillus thuringiensis and Its Pesticidal Crystal Proteins," Microbiology and Molecular Biology Reviews, Vol. 62, No. 3, 1998, pp. 775-806.

[9] K. F. Chak, D. C. Chao, M. Y. Tseng and S. S. Kao, "Determination and Distribution of Cry-Type Genes of Bacillus thuringiensis Isolates from Taiwan," Applied and Environmental Microbiology, Vol. 60, No. 7, 1994, pp. 2415-2420.

[10] A. Bravo, S. Sarabia, L. López and H. Ontiveros, "Characterization of Cry Genes in a Mexican Bacillus thuringiensis Strain Collection," Applied and Environmental Microbiology, Vol. 64, No. 12, 1998, pp. 4965-4972.

[11] J. E. Ibarra, M. C. Del Rincon, S. Orduz and D. Noriega, "Diversity of Bacillus thuringiensis Strains from Latin America with Insecticidal Activity against Different Mosquito Species," Applied and Environmental Microbiology, Vol. 69, No. 9, 2003, pp. 5269-5274.

[12] E. Quesada-Moraga, E. García-Tovar, P. Valverde-García and C. Santiago-Álvarez, "Isolation, Geographical Diversity and Insecticidal Activity of Bacillus thuringiensis from Soils in Spain," Microbiology Research, Vol. 159, No. 1, 2004, pp. 59-71.

[13] C. Itoua-Apoyolo, L. Drif, J. M. Vassal, H. DeBarjac, J. P. Bossy, F. Leclant and R. Frutos, "Isolation of Multiple Subspecies of Bacillus thuringiensis from a Population of the European Sunflower Moth, Homoeosoma nebulella," Applied and Environmental Microbiology, Vol. 61, No. 12, 1995, pp. 4343-4347.

[14] G. Karamanlidou, A. F. Lambropoulos, S. I. Koliais, T. Manousis, D. Ellar and C. Kastritsis, "Toxicity of Bacillus thuringiensis to Laboratory Populations of the Olive Fruit Fly (Dacus oleae)," Applied and Environmental Microbiology, Vol. 57, No. 8, 1991, pp. 2277-2282.

[15] T. M. Alberola, S. Aptosoglou, M. Arsenakis, Y. Bel, G. Delrio, D. J. Ellar, J. Ferre, S. P. Gash, F. Granero, S. Koliais, M. J. Martinez-Sebastian, R. Prota, S. Rubino, A. Satta, G. Scarpellini, A. Sivropoulou and E. Vasara, "Insecticidal Activity of Strains of Bacillus thuringiensis on Larvae and Adults of Bactrocera oleae Gmelin (Dipt. Tephritidae)," Journal of Invertebrate Pathology, Vol. 74, No. 2, 1999, pp. 127-136.

[16] D. C. Robacker, A. J. Martínez, J. A. García, M. Díaz and C. Romero, "Toxicity of Bacillus thuringiensis to Mexican Fruit Fly (Diptera: Tephritidae)," Journal of Economic Entomology, Vol. 89, No. 1, 1996, pp. 104-110.

[17] J. Toledo, P. Liedo, T. Williams and J. Ibarra, "Toxicity of Bacillus thuringiensis $\beta$-Exotoxin to Three Species of Fruit Flies (Diptera: Tephritidae)", Journal of Economic Entomology, Vol. 92, No. 5, 1999, pp. 1052-1056.

[18] R. E. Gingrich, "Demonstration of Bacillus thuringiensis as a Potential Control Agent for the Adult Mediterranean 
Fruit Fly, Ceratitis capitata (Wied.)," Journal of Applied Entomology, Vol. 104, No. 1-5, 1987, pp. 378-385.

[19] F. Hassani and N. Gaouar Benyelles, "Application of Bacillus thuringiensis (Bti) Struggling Microbiological Control of the Fruit Fly Ceratitis capitata (wied) (Diptera: Tephritidae)," IBSCientific Journal of Science, Vol. 3, No. 1, 2008, pp. 10-13.

[20] J. C. Vidal-Quist, P. Castañera and J. González-Cabrera, "Diversity of Bacillus thuringiensis Strains Isolated from Citrus Orchards in Spain and Evaluation of Their Insecticidal Activity against Ceratitis capitata," Journal of Microbiology and Biotechnology, Vol. 19, No. 8, 2009, pp. 749-759.

[21] Y. Bel, F. Granero, T. M. Alberola, M. J. MartínezSebastian and J. Ferré, "Distribution, Frequency and Diversity of Bacillus thuringiensis in Olive Tree Environments in Spain," Systematic and Applied Microbiology, Vol. 20, No. 4, 1997, pp. 652-658.

[22] G. S. A. B. Stewart, K. Johnstone, E. Hagelberg and D. J. Ellar, "Commitment of Bacterial Spores to Germinate," Biochemistry Journal, Vol. 198, No. 1, 1981, pp. 101-106.
[23] E. Helgason, O. A. Okstad, D. A. Caugant, H. A. Johansen, A. Fouet, M. Mock, I. Hegna and A. B. Kolsto, "Bacillus Anthracis, Bacillus cereus, and Bacillus thuringiensis - One Species on the Basis of Genetic Evidence," Applied and Environmental Microbiology, Vol. 66, No. 6, 2000, pp. 2627-2630.

[24] J. A. Baum and T. Malvar, "Regulation of insecticidal crystal protein production in Bacillus thuringiensis," Molecular Microbiology, Vol. 18, No. 1, 1995, pp. 1-12.

[25] C. A. Molina, J. F. Cana-Roca, A. Osuna and S. Vilchez, "Selection of a Bacillus pumilus Strain Highly Active against Ceratitis capitata (Wiedemann) Larvae," Applied and Environmental Microbiology, Vol. 76, No. 5, 2010, pp. 1320-1327.

[26] C. Yamvrias and M. Anagnou, "Preliminary Tests on the Sensitivity of the Larvae of Dacus oleae to Bacillus thuringiensis var. israelensis, in Fruit Flies of Economic Importance," R. Cavalloro, Ed., Balkema, Rotterdam, Vol. 87, 1989, pp. $345-348$. 